OPEN ACCESS

Edited by: Kazim Sahin,

Firat University, Turkey

Reviewed by:

Ayhan Dogukan,

Firat University, Turkey

Cemal Orhan,

Firat University, Turkey

Pedro Magalhães,

Agostinho Neto University, Angola

*Correspondence:

Silvia Lai

silvia.lai@uniroma1.it

Specialty section: This article was submitted to

Clinical Nutrition,

a section of the journal

Frontiers in Nutrition

Received: 06 October 2016 Accepted: 21 February 2017

Published: 17 March 2017

Citation:

Lai S, Amabile MI, Altieri S,

Mastroluca D, Lai C, Aceto P,

Crudo M, D'Angelo AR, Muscaritoli $M$

and Molfino A (2017) Effect of

Underlying Renal Disease on

Nutritional and Metabolic Profile of

Older Adults with Reduced Renal

Function.

Front. Nutr. 4:4.

doi: 10.3389/fnut.2017.00004

\section{Effect of Underlying Renal Disease on Nutritional and Metabolic Profile of Older Adults with Reduced Renal Function}

\author{
Silvia Lai ${ }^{1 *}$, Maria Ida Amabile', Silvia Altieri², Daniela Mastroluca ${ }^{3}$, Carlo Lai ${ }^{4}$, \\ Paola Aceto ${ }^{5}$, Massimiliano Crudo ${ }^{6}$, Anna Rita D'Angelo ${ }^{7}$, Maurizio Muscaritoli ${ }^{1}$ and \\ Alessio Molfino ${ }^{1}$
}

${ }^{1}$ Department of Clinical Medicine, Sapienza University of Rome, Rome, Italy, ${ }^{2}$ Department of Clinical and Molecular Medicine, Sapienza University of Rome, UOC Nephrology, Sant' Andrea Hospital, Rome, Italy, ${ }^{3}$ Nephrology and Dialysis Unit, Hospital ICOT Latina, Sapienza University of Rome, Rome, Italy, ${ }^{4}$ Department of Dynamic and Clinic Psychology, Sapienza University of Rome, Rome, Italy, ${ }^{5}$ Department of Anesthesiology and Intensive Care, Catholic University of Sacred Heart Rome, Rome, Italy, ${ }^{6}$ Software House INTECS S.p.A., Rome, Italy, ${ }^{7}$ Department of Obstetrical-Gynecological Sciences and Urologic Sciences, Sapienza University of Rome, Rome, Italy

Background: Chronic kidney disease is a common condition in the general population, particularly among older adults. Renal impairment is in turn associated with metabolic and nutritional derangements and with increased risk of cardiovascular disease.

Aim: To compare the metabolic, nutritional, and cardiovascular impact of reduced kidney function between patients with and without known renal disease.

Materials and Methods: We enrolled consecutive outpatients (age $\geq 65$ years) with reduced renal function who were divided into two groups: Group A with history of renal disease and Group B with unknown renal disease. Metabolic and nutritional parameters, including involuntary body weight loss (BWL) in the previous 6 months, mineral metabolism, inflammatory indices, and left ventricular mass index (LVMI), were evaluated.

Results: A total of 76 patients were enrolled. Group A ( $n=39, \mathrm{M}: 24, \mathrm{~F}: 15)$ showed greater BWL with a significant reduction of 25-hydroxyvitamin D, transferrin, cholinesterase, albumin, and LVMI with respect to Group B $(p<0.01)$. Conversely, Group B ( $n=37, \mathrm{M}: 23, \mathrm{~F}: 14$ ) showed significantly increased intact parathyroid hormone, total cholesterol, low-density lipoprotein, triglycerides, and C-reactive protein when compared to Group A ( $p<0.05)$.

Conclusion: The positive history of renal disease may negatively impact on several metabolic and nutritional parameters related to increased cardiovascular risk among older adults.

Keywords: older adults, chronic kidney disease, cardiovascular disease, inflammation, weight loss 


\section{INTRODUCTION}

Chronic kidney disease (CKD) is a common condition and it is increasing worldwide, particularly in adults aged $\geq 70$ years, where the prevalence in the United States, Europe, and China is 47,35 , and $28 \%$, respectively $(1,2)$. The current Kidney Disease Outcomes Quality Initiative (KDOQI) classification system for CKD is mainly based on the reduction of estimated glomerular filtration rate (eGFR), which should be persistent for more than 3 months, and it is classified in five stages (3). Epidemiological studies using this classification have highlighted that approximately $10 \%$ of the adults and $20-54 \%$ of the older adults suffer from CKD in stages 3-5 $(4,5)$. However, we do not have yet a nomogram of the measurement in a large sample of healthy individuals across the age spectrum of $20-80$ years (5-7). The prevalence of CKD is particularly high in older adults, although the risk for progression to end-stage renal disease (ESRD) among older CKD patients is low. Therefore, the diagnosis of CKD should require an eGFR inappropriately low, as a consequence of a known disease, and/or the presence of abnormally elevated proteinuria or albuminuria (8-10). In particular, Hallan et al. (9) suggested to consider in CKD stage 3 the presence of micro-, normo-, or macro-albuminuria to improve the diagnostic accuracy for the progression to ESRD. Several studies, including the Nord-Trøndelag Health Study 2 (11-13), showed that lower eGFR and increased albuminuria in 24-h urine collection and increased albumin:creatinine ratio are relevant independent risk factors among older adults.

The question then arises whether this lower eGFR is a consequence of known kidney disease or if it is the result of aging and whether a stable low eGFR in older adults is sufficient or not to satisfy a homeostatic demand. Homeostatic failure occurs when eGFR is $<60 \mathrm{ml} / \mathrm{min} / 1.73 \mathrm{~m}^{2}$ and, with higher prevalence, when it is $<45 \mathrm{ml} / \mathrm{min} / 1.73 \mathrm{~m}^{2}(1,13)$.

The aim of this study was to compare patients with known renal disease and those with eGFR $<60 \mathrm{ml} / \mathrm{min}$ without known disease and to evaluate whether this differentially impacts patients' metabolic, nutritional, and cardiovascular parameters.

\section{MATERIALS AND METHODS}

\section{Study Design and Subjects}

We performed an observational study on consecutive stable outpatients from the Nephrology Unit of Policlinico Umberto I, Sapienza University of Rome, Italy. The study was approved by the clinical research ethics committee of our University Hospital. The study conforms to the principles outlined in the Declaration of Helsinki and we obtained a written consent from each patient enrolled in this study. Patients with eGFR 30-60 ml/min were recruited in the period from January 2013 to August 2015. Exclusion criteria were heart failure, underlying malignancy, chronic liver disease, chronic obstructive pulmonary disease, cerebrovascular disease, acute myocardial infarction, and acute coronary syndrome reported in the previous 3 months. We also excluded patients who refused to give consent and patients with missing data. Patients were divided into two groups: Group A included patients with known renal disease and Group B those with eGFR $<60 \mathrm{ml} / \mathrm{min}$ without known renal disease.

The Chronic Kidney Disease Epidemiology Collaboration equation was used to calculate $\operatorname{eGFR}(5,14)$. Additionally, the presence of comorbidities, including diabetes and arterial hypertension, and current therapies were collected. Patients in both groups were allowed to continue their therapy with statins, antihypertensive, and antiplatelet drugs.

\section{Anthropometric Assessment}

Body weight was determined to the nearest $0.1 \mathrm{~kg}$ using a calibrated digital scale. Body mass index (BMI) was calculated by the formula [weight $(\mathrm{kg}) /$ height $^{2}\left(\mathrm{~m}^{2}\right)$ ]. We also calculated the body weight loss in the previous 6 months.

\section{Laboratory Measurements}

Blood samples were collected after an overnight fasting of at least $12 \mathrm{~h}$. In all patients, the levels of fasting plasma glucose, total serum cholesterol, high-density lipoprotein (HDL), lowdensity lipoprotein (LDL), triglycerides, Blood Urea Nitrogen (BUN), serum calcium, phosphate, sodium, potassium, serum uric acid, iron metabolism, including transferrin, cholinesterase, C-reactive protein (CRP), and erythrocyte sedimentation rate (ESR) were measured using standard automated techniques. Serum albumin was determined by bromocresol purple method. Parathyroid hormone was measured using a two-site assay that measures "intact" hormone (iPTH) (pg/mL) and 25-hydroxyvitamin $\mathrm{D}(25-\mathrm{OH}$ Vit $\mathrm{D})(\mathrm{ng} / \mathrm{mL})$ by radioimmunoassay. LDL cholesterol was calculated using the Friedewald equation: $\mathrm{LDL}=$ total cholesterol $-\mathrm{HDL}-$ (triglycerides/5). Arterial blood gas analysis was performed using a blood gas analyzer (Nova Phox Plus C). We have measured albuminuria in 24-h urine (15).

\section{Echocardiography}

M-mode 2D echocardiographic examinations by a single experienced sonographer in the echocardiography laboratory and using a standard institutional protocol were completed. Commercially available instruments (Toshiba Aplio xV, Toshiba American Medical Systems, Inc., Tustin, CA, USA) equipped with 2.25 - to $7.5-\mathrm{MHz}$ imaging transducers were used. The subjects were in the left decubitus position, and the sonographer was blinded to all clinical details of the patients (16). All echocardiographic data according to the guidelines of the American Society of Echocardiography were recorded (17). The end-diastolic and end-systolic left ventricular internal diameter (LVED and LVES, respectively), interventricular septum thickness, and posterior wall thickness were measured. The left ventricular mass by Devereux's formula normalized by body surface area and height was estimated, and its index (LVMI) was also calculated (18).

\section{Statistical Analysis}

Data management and analysis were performed using the $\mathrm{IBM}^{\circledR}$ SPSS $^{\circledR}$ Statistics 18 for Windows ${ }^{\circledR}$ software (IBM Corporation, Armonk, NY, USA). The normality of variables was tested by the method of Kolmogorov-Smirnov test for normal distributions. 
All continuous variables were expressed as mean $\pm S D$, and categorical variables were expressed as number (percentage). Student's $t$-test or Mann-Whitney $U$-test was performed to determine differences between groups. Binomial test or Chisquare test was used for comparison of categorical data. Pearson's or Spearman's correlation was used to determine the relationship and the strength of association between the variables in bivariate correlation. Potential confounders, such as age and gender, were included in the analyses when comparing the two groups. A $p$ value $<0.05$ was considered statistically significant.

\section{RESULTS}

The study included 76 consecutive patients, 29 females and 47 males, with a mean age of $70 \pm 5.4$ years.

Patient's characteristics are shown in Table 1. There were no significant differences between the two groups regarding sex, age, eGFR $(\mathrm{mL} / \mathrm{min})$, creatinine $(\mathrm{mg} / \mathrm{dL})$, sodium $(\mathrm{mEq} / \mathrm{L})$, potassium $(\mathrm{mEq} / \mathrm{L})$, calcium $(\mathrm{mg} / \mathrm{dL})$, phosphorus $(\mathrm{mg} / \mathrm{dL})$, serum uric acid $(\mathrm{mg} / \mathrm{dL}), \mathrm{HDL}(\mathrm{mg} / \mathrm{dL})$, and bicarbonates $(\mathrm{mEq} / \mathrm{L})$ (Tables 1 and 2).

Group A showed lower albumin (g/dL) $(p<0.0001)$, cholinesterase $(\mathrm{UI} / \mathrm{mL})(p=0.003)$, transferrin $(\mathrm{mg} / \mathrm{dL})(p=0.001)$,

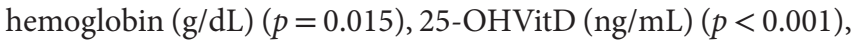
and $\mathrm{pH}(p<0.0001)$ with respect to Group B (Table 2). Moreover, Group A showed greater body weight loss (BWL) in the previous 6 months with respect to Group B $(p=0.009)$, higher LVMI $\mathrm{g} / \mathrm{m}^{2}(p<0.0001)$, BUN $(\mathrm{mg} / \mathrm{dL})(p<0.001)$, iPTH $(\mathrm{pg} / \mathrm{mL})$ $(p=0.03)$, total cholesterol $(\mathrm{mg} / \mathrm{dL})(p=0.02), \mathrm{LDL}(\mathrm{mg} / \mathrm{dL})$ $(p=0.04)$, triglycerides $(\mathrm{mg} / \mathrm{dL})(p=0.02)$, CRP $(\mathrm{mg} / \mathrm{dL})$ $(p=0.046)$, and ESR $(\mathrm{mm} / \mathrm{h})(p=<0.0001)$ (Tables 1 and 2$)$. The patients in Group B had reached the target blood pressure level by monotherapy, while those in Group A were in treatment with polytherapy. Proteinuria showed a different behavior in Group A and B. In fact, in Group A 16 out of 39 patients (41\%)

TABLE 1 | Patient's demographic and clinical characteristics.

\begin{tabular}{lccc}
\hline $\boldsymbol{N}$ patients = 76 & $\begin{array}{c}\text { Group A } \\
(\mathbf{N = 3 9 )}\end{array}$ & $\begin{array}{c}\text { Group B } \\
(\mathbf{N = 3 7 )}\end{array}$ & $\boldsymbol{p}$ \\
\hline Female $(N)$ & 15 & 14 & 0.86 \\
Age (year) & $71.2 \pm 4.4$ & $72.3 \pm 4.3$ & 0.27 \\
Body mass index (kg/m²) & $23.5 \pm 3.8$ & $26.1 \pm 3.5$ & $\mathbf{0 . 0 0 3}$ \\
eGFR (mL/min) & $48.2 \pm 10.3$ & $52.6 \pm 10.5$ & 0.07 \\
BUN (mg/dL) & $48.13 \pm 16.49$ & $31.49 \pm 8.73$ & $<\mathbf{0 . 0 0 1}$ \\
Creatinine (mg/dL) & $1.7 \pm 0.42$ & $1.6 \pm 0.54$ & 0.37 \\
Sodium (mEq/L) & $139.1 \pm 2.1$ & $139.3 \pm 1.8$ & 0.66 \\
Potassium (mEq/L) & $4.1 \pm 0.7$ & $4.0 \pm 0.5$ & 0.48 \\
Calcium (mg/dL) & $9.2 \pm 0.3$ & $9.4 \pm 0.6$ & 0.07 \\
Phosphorus (mg/dL) & $4.5 \pm 0.5$ & $4.3 \pm 0.4$ & 0.06 \\
Arterial hypertension $(N)$ & 38 & 15 & $<\mathbf{0 . 0 0 0 1}$ \\
Diabetes mellitus $(N)$ & 27 & 0 & $<\mathbf{0 . 0 0 0 1}$ \\
Chronic pyelonephritis $(N)$ & 3 & 0 & 0.26 \\
Chronic glomerulonephritis $(N)$ & 7 & 0 & $\mathbf{0 . 0 2}$ \\
\end{tabular}

Data are shown as mean $\pm S D$.

eGFR, estimated glomerular filtration rate; BUN, Blood Urea Nitrogen.

Bold values indicate statistically significant $p$ values. had proteinuria $>1 \mathrm{~g} / 24 \mathrm{~h}$. In Group B, proteinuria was present in only 7 out of 37 patients (19\%), and it was $<1 \mathrm{~g} / 24 \mathrm{~h}$.

\section{DISCUSSION}

The results obtained in the present study would suggest that agerelated compared to renal disease-related decline in renal function differentially impacts on patients' metabolic and nutritional parameters, and possibly on cardiovascular disease (CVD) risk.

Chronic kidney disease is a common feature among older adults and less frequently progresses to ESRD with respect to younger patients (13). CVD is the most common cause of morbidity and mortality associated with CKD, due to well-known cardiovascular risk factors in older patients and to several novel risk factors associated with $\mathrm{CKD}$, such as abnormal nutritional and metabolic parameters.

In a large number of CKD patients most of these risk factors are present when eGFR is $60 \mathrm{ml} / \mathrm{min} / 1.73 \mathrm{~m}^{2}$ or less (13). However, the relative risk associated with traditional risk factors, such as hypertension and hypercholesterolemia, is lower in older patients compared to younger ones. In older patients, there is an inverse relationship between traditional CVD risk factors, such as BMI, blood pressure, cholesterol, and all-cause mortality (19), while altered nutritional and metabolic derangements may represent negative prognostic factors in CKD.

In our study, we found that older adults with known renal disease have a worse nutritional and metabolic status with respect to patients without a known renal disease. This is reflected by the presence of alteration of metabolic and inflammatory profile and by altered cardiovascular index (LVMI), although the eGFR was comparable between the two groups.

TABLE 2 | Patient's nutritional, metabolic, inflammatory, and cardiac variables.

\begin{tabular}{|c|c|c|c|}
\hline$N$ patients $=76$ & Group A $(N=39)$ & Group B $(N=37)$ & $p$ \\
\hline Albumin (g/dL) & $3.73 \pm 0.51$ & $4.69 \pm 0.40$ & $<0.0001$ \\
\hline Cholinesterase (UI/mL) & $7312 \pm 2864$ & $9647 \pm 3637$ & 0.003 \\
\hline Transferrin (mg/dL) & $218.40 \pm 37.68$ & $266.22 \pm 78.71$ & 0.001 \\
\hline Hemoglobin (g/dL) & $12.0 \pm 0.9$ & $14.2 \pm 5.6$ & 0.015 \\
\hline 25-OHVitD (ng/mL) & $15.36 \pm 10.65$ & $26.06 \pm 12.91$ & $<0.0001$ \\
\hline iPTH (pg/mL) & $91.4 \pm 57.7$ & $67.6 \pm 29.9$ & 0.03 \\
\hline Total cholesterol (mg/dL) & $190 \pm 32$ & $163 \pm 25$ & $<0.001$ \\
\hline $\mathrm{HDL}(\mathrm{mg} / \mathrm{dL})$ & $50.2 \pm 11.8$ & $44.8 \pm 12.0$ & 0.05 \\
\hline $\mathrm{LDL}(\mathrm{mg} / \mathrm{dL})$ & $112.0 \pm 37.1$ & $95.9 \pm 21.0$ & 0.02 \\
\hline Triglycerides (mg/dL) & $155 \pm 71$ & $118 \pm 47$ & 0.01 \\
\hline Serum uric acid (mg/dL) & $4.7 \pm 1.1$ & $4.3 \pm 0.9$ & 0.09 \\
\hline $\mathrm{pH}$ & $7.35 \pm 0.04$ & $7.40 \pm 0.03$ & $<0.0001$ \\
\hline Bicarbonates (mEq/L) & $21.7 \pm 4.1$ & $23.0 \pm 1.8$ & 0.10 \\
\hline $\mathrm{CRP}^{\mathrm{a}}(\mathrm{mg} / \mathrm{dL})$ & $0.23(0.13 ; 0.31)$ & 0.13 (0.08; 0.29) & 0.046 \\
\hline $\operatorname{ESR}(\mathrm{mm} / \mathrm{h})$ & $27.7 \pm 16.9$ & $16.3 \pm 11.2$ & $<0.0001$ \\
\hline Body weight loss ${ }^{a}(\%)$ & $3.19(0 ; 5.97)$ & $1.78(-4.05 ; 1.83)$ & 0.009 \\
\hline LVMI $\left(\mathrm{g} / \mathrm{m}^{2}\right)$ & $141 \pm 16$ & $103 \pm 20$ & $<0.0001$ \\
\hline
\end{tabular}

Data are shown as mean $\pm S D$.

aMedian (interquartile range) is shown for non-normally distributed variable. 25-OHVitD, 25-hydroxyvitamin D; iPTH, intact parathyroid hormone; HDL, high-density lipoprotein; LDL, low-density lipoprotein; CRP, C-reactive protein; ESR, erythrocyte sedimentation rate; LVMI, left ventricular mass index.

Bold values indicate statistically significant $p$ values. 
Only patients in Group B achieved the lipid target range recommended by the European and Canadian guidelines (20), although the recent American guidelines give more importance to the modification of lifestyles, instead of targeting strict lipid levels (21). Considering the high prevalence of diabetes among patients in Group A, the cholesterol levels were above the recommended range, representing a further relevant risk factor for cardiovascular events. Also, triglycerides were significantly higher in Group A with respect to Group B (>150 mg/dl) (20).

The KDOQI classification considers the eGFR of $50 \mathrm{ml} /$ $\mathrm{min} / 1.73 \mathrm{~m}^{2}$ as indicative of moderate CKD (stage 3 ), independent of age. It has been recognized that the physiological aging process of the kidney leads to a loss of GFR at a rate of about $1 \mathrm{ml} / \mathrm{min} / 1.73 \mathrm{~m}^{2}$ per year after 40 years of age $(22,23)$. Two large studies found that moderate reductions in eGFR were not associated with increased mortality among older adults (i.e., $\geq 60$ years of age in one study and $\geq 65$ years in the other study) $(24,25)$. In contrast, in a meta-analysis performed by the Chronic Kidney Disease Prognosis Consortium (26), an association was present between eGFR $<60 \mathrm{ml} / \mathrm{min} / 1.73 \mathrm{~m}^{2}$ and increased all-cause and cardiovascular mortality among adults $\leq 65$ years of age and their counterparts $\geq 65$ years of age (27).

Conversely, in a large cohort of veterans who fulfilled criteria for CKD stage 3 or higher, the prognostic implications of eGFR for death and ESRD varied greatly depending on the age (28). Moreover, Davies and Shock (29) showed that mean GFR (measured using the gold standard of inulin clearance) decreased from $123 \mathrm{ml} / \mathrm{min} / 1.73 \mathrm{~m}^{2}$ at age $20-29$ years to $65 \mathrm{ml} / \mathrm{min} / 1.73 \mathrm{~m}^{2}$ at age $80-89$ years.

Cross-sectional evaluations of measured GFR and eGFR in healthy individuals, e.g., potential kidney donors, showed a reduction in the mean value of $6-8 \mathrm{ml} / \mathrm{min} / 1.73 \mathrm{~m}^{2}$ per decade (30). This indicates that there is a real reduction in renal function among older adults. Available data showed that, at least until the age of 80 years, the renal functional reserve, i.e., the increase in eGFR after an amino acid load, was preserved in these subjects independent of gender $(31,32)$. Hollenberg et al. (33) demonstrated a reduction of the renal vasodilatory response to acetylcholine in older kidney donors. Furthermore, the arterial wall is substantially remodeled with aging even in the healthy subjects. Histological changes such as glomerulosclerosis, tubular atrophy, interstitial fibrosis, and arteriolar sclerosis, which are typical findings of the common pathway of progressive CKD, are increasingly found with aging even in the absence of hypertension and diabetes or other chronic diseases $(4,12)$. Data from the PREVEND study have shown that eGFR were independently and significantly associated with cardiovascular events only in subjects $<60$ years of age (34). Indeed, a stable low eGFR in older adults, provided that it is physiologically sufficient to meet homeostatic demands, cannot be considered as a disease per se and rarely progresses to kidney failure, even if it implies a reduced reserve and vulnerability to drugs overdosing and increased risk of acute kidney injury (AKI) (13).

The complications related to reduced eGFR would be abnormal sodium balance causing hypertension, a blunted erythropoietin axis causing anemia, and disturbed calcium and phosphate balance causing secondary hyperparathyroidism and metabolic acidosis (11).

In our study, the homeostatic and metabolic disorders were significantly increased in patients with positive history of renal disease (Group A), although also patients with no history for disease (Group B) showed depletion of vitamin D. In particular, Group A showed a more pronounced depletion of vitamin D with respect to Group B, being associated with a small but significant increase of iPTH. Moreover, Group A showed a worsening trend of nutritional status, with a significant reduction in albumin and cholinesterase levels, lower BMI, and greater BWL in the previous 6 months. In Group A, we also found a significant reduction in hemoglobin levels, although these values were within the therapeutic range for patients with eGFR $\leq 60 \mathrm{ml} / \mathrm{min}$ (35), and they were associated with mild iron deficiency and increased inflammatory status. We observed significant increase of LVMI in Group A, which might be influenced by several factors, including hyperparathyroidism, and by the higher rate of hypertension documented within this group. Based on these observations, patients with history of renal disease may require a more careful follow-up visit, with assessment of nutritional and metabolic status compared with those with similar eGFR but with unknown underlying renal disease. These findings question the clinical relevance of a standard stage-based approach to the management of CKD, which is supported in most of the available international guidelines and focus on the critical need to use stronger prognostic tools for an early identification of older adults who will progress from CKD to ESRD, CVD, or AKI (36). Moreover, the current staging system for CKD is largely based on the concept that GFR $\geq 90 \mathrm{ml} / \mathrm{min} / 1.73 \mathrm{~m}^{2}$ is normal, $60-89 \mathrm{ml} / \mathrm{min} / 1.73 \mathrm{~m}^{2}$ is reduced, and $\leq 60 \mathrm{ml} / \mathrm{min} / 1.73 \mathrm{~m}^{2}$ is always abnormal, independent of the presence of kidney damage $(37,38)$. This approach does not take into account the biological variability and the renal reserve $(39,40)$.

The average eGFR is variably decreased in older adults, as a consequence of biological aging and underlying comorbidities (41). In some patients, the decline of renal function is enhanced by concomitant CVDs, and a low eGFR may be the consequence of aging and concomitant underlying diseases $(42,43)$.

As supported by other evidences, in older patients with CKD we should consider not only the eGFR and the presence of proteinuria but also the underlying renal disease $(44,45)$. Moreover, we should assess in this population the nutritional and metabolic status in order to better stratify cardiovascular risk and to implement tailored therapeutic interventions $(46,47)$.

We acknowledge the limitations of our study. The small sample size might have limited the possibility to recognize associations between patients' clinical characteristics. In this light, the present cohort of patients may not be representative of the entire CKD outpatient population. In particular, we included a large proportion of patients on antiplatelet and antihypertensive therapies and on statins and the potential impact of hypertension, hypercholesterolemia, and their treatments on LVMI may have potentially confounded our results. Although both groups were affected by hypertension, Group A had a higher prevalence of this condition probably determining the significant difference 
observed in LVMI. Approximately $40 \%$ of patients in Group B suffered hypertension. This may be associated with the reduction of eGFR. However, in contrast with Group A, patients in Group B were treated with antihypertensive monotherapy, showing blood pressure values within normal range.

\section{CONCLUSION}

In spite of comparable eGFR, older adults with underlying renal disease have a worse nutritional and metabolic balance with respect to patients with negative history. This is reflected by the presence of alterations of metabolic and inflammatory profile and by impaired cardiovascular index.

Integrated care for older adults with loss of renal function should go beyond a focus on reduced eGFR or proteinuria and include consideration of underlying cause of kidney disease.

Based on our results, it might be helpful to prospectively evaluate the impact of nutritional alterations on clinical outcomes and health-care costs in older adults with impaired renal function.

\section{REFERENCES}

1. Hallan SI, Orth SR. The conundrum of chronic kidney disease classification and end-stage renal risk prediction in the elderly-what is the right approach? Nephron Clin Pract (2010) 116:307-16. doi:10.1159/000319166

2. Coresh J, Selvin E, Stevens LA, Manzi J, Kusek JW, Eggers P, et al. Prevalence of chronic kidney disease in the United States. JAMA (2007) 298:2038-47. doi:10.1001/jama.298.17.2038

3. Eckardt KU, Berns JS, Rocco MV, Kasiske BL. Definition and classification of CKD: the debate should be about patient prognosis-a position statement from KDOQI and KDIGO. Am J Kidney Dis (2009) 53:915-20. doi:10.1053/ j.ajkd.2009.04.001

4. Raymond NT, Zehnder D, Smith SC, Stinson JA, Lehnert H, Higgins RM. Elevated relative mortality risk with mild-to-moderate chronic kidney disease decreases with age. Nephrol Dial Transplant (2007) 22:3214-20. doi:10.1093/ ndt/gfm396

5. Delanaye P, Cavalier E, Mariat C, Maillard N, Krzesinski JM. MDRD or CKD-EPI study equations for estimating prevalence of stage $3 \mathrm{CKD}$ in epidemiological studies: which difference? Is this difference relevant? BMC Nephrol (2010) 11:8. doi:10.1186/1471-2369-11-8

6. Juutilainen A, Kastarinen H, Antikainen R, Peltonen M, Salomaa V, Tuomilehto J, et al. Comparison of the MDRD Study and the CKD-EPI Study equations in evaluating trends of estimated kidney function at population level: findings from the National FINRISK Study. Nephrol Dial Transplant (2012) 27:3210-7. doi:10.1093/ndt/gfs047

7. Matsushita K, Mahmoodi BK, Woodward M, Emberson JR, Jafar TH, Jee SH, et al. Comparison of risk prediction using the CKD-EPI equation and the MDRD study equation for estimated glomerular filtration rate. JAMA (2012) 307:1941-51. doi:10.1001/jama.2012.3954

8. Hallan S, Astor B, Romundstad S, Aasarød K, Kvenild K, Coresh J. Association of kidney function and albuminuria with cardiovascular mortality in older versus younger individuals: the HUNT II study. Arch Intern Med (2007) 167:2490-6. doi:10.1001/archinte.167.22.2490

9. Hallan SI, Ritz E, Lydersen S, Romundstad S, Kvenild K, Orth SR. Combining GFR and albuminuria to classify CKD improves prediction of ESRD. J Am Soc Nephrol (2009) 20:1069-77. doi:10.1681/ASN.2008070730

10. Tonelli M, Muntner P, Lloyd A, Manns BJ, James MT, Klarenbach S, et al. Using proteinuria and estimated glomerular filtration rate to classify risk in patients with chronic kidney disease: a cohort study. Ann Intern Med (2011) 154:12-21. doi:10.7326/0003-4819-154-1-201101040-00003

11. Hallan S, Astor BC, Lydersen S. Estimating glomerular filtration rate in the general population: the second Health Survey of Nord Trondelag (HUNT II). Nephrol Dial Transplant (2006) 21:1525-33. doi:10.1093/ndt/gfl035

\section{AUTHOR CONTRIBUTIONS}

SL, MIA, MM, and AM made substantial contributions to conception and design and interpretation of data; $\mathrm{SA}, \mathrm{DM}$, and $\mathrm{AD}$ made substantial contributions to acquisition of data; and CL, PA, and MC made substantial contributions to analysis of data. All authors participated in drafting the article or revising it critically for important intellectual content. All authors gave final approval of the version to be submitted.

\section{ACKNOWLEDGMENTS}

The authors acknowledge the Study Group on Geriatric Nephrology of the Italian Society of Nephrology (SIN) for supporting this research.

\section{FUNDING}

The study was funded by Institutional funds (Department of Clinical Medicine, Sapienza University of Rome).

12. Warnock DG, Muntner P, McCullough PA, Zhang X, McClure LA, Zakai N, et al. Kidney function, albuminuria, and all-cause mortality in the REGARDS (Reasons for Geographic and Racial Differences in Stroke) study. Am J Kidney Dis (2010) 56:861-71. doi:10.1053/j.ajkd.2010.05.017

13. Winearls CG, Glassock RJ. Classification of chronic kidney disease in the elderly: pitfalls and errors. Nephron Clin Pract (2011) 119:2-4. doi: $10.1159 / 000328013$

14. Levey AS, Stevens LA, Schmid CH, Zhang YL, Castro AF III, Feldman HI, et al. A new equation to estimate glomerular filtration rate. Ann Intern Med (2009) 150:604-12. doi:10.7326/0003-4819-150-9-200905050-00006

15. Lai S, Mariotti A, Coppola B, Lai C, Aceto P, Dimko M, et al. Uricemia and homocysteinemia: nontraditional risk factors in the early stages of chronic kidney disease-preliminary data. EurRev Med Pharmacol Sci (2014) 18:1010-7.

16. Lai S, Dimko M, Galani A, Coppola B, Innico G, Frassetti N, et al. Early markers of cardiovascular risk in chronic kidney disease. Ren Fail (2014) 37:254-61. doi:10.3109/0886022X.2014.982489

17. Lang RM, Bierig M, Devereux RB, Flachskampf FA, Foster E, Pellikka PA, et al. Recommendations for chamber quantification: a report from the American Society of Echocardiography's Guidelines and Standards Committee and the Chamber Quantification Writing Group, developed in conjunction with the European Association of Echocardiography, a branch of the European Society of Cardiology. J Am Soc Echocardiogr (2005) 18:1440-63.

18. Molfino A, Papa A, Gasperini-Zacco ML, Muscaritoli M, Amoroso A, Cascino A, et al. Left ventricular mass correlates with lean body mass in patients with disease-associated wasting. J Cachexia Sarcopenia Muscle (2014) 5(3):251-2. doi:10.1007/s13539-014-0148-8

19. Boshuizen HC, Izaks GJ, van Buuren S, Ligthart GJ. Blood pressure and mortality in elderly people aged 85 and older: community based study. BMJ (1998) 316:1780-4. doi:10.1136/bmj.316.7147.1780

20. Ray KK, Kastelein JJ, Boekholdt SM, Nicholls SJ, Khaw KT, Ballantyne CM, et al. The ACC/AHA 2013 guideline on the treatment of blood cholesterol to reduce atherosclerotic cardiovascular disease risk in adults: the good the bad and the uncertain: a comparison with ESC/EAS guidelines for the management of dyslipidaemias 2011. Eur Heart J (2014) 35(15):960-8. doi:10.1093/ eurheartj/ehu107

21. Stone NJ, Robinson JG, Lichtenstein AH, Bairey Merz CN, Blum CB, Eckel RH, et al. 2013 ACC/AHA guideline on the treatment of blood cholesterol to reduce atherosclerotic cardiovascular risk in adults: a report of the American College of Cardiology/American Heart Association Task Force on Practice Guidelines. Circulation (2014) 63(25 Pt B):2889-934. doi:10.1161/ CIRCRESAHA.114.303996

22. O'Hare AM, Bertenthal D, Covinsky KE, Landefeld CS, Sen S, Mehta $\mathrm{K}$, et al. Mortality risk stratification in chronic kidney disease: one 
size for all ages? JAm Soc Nephrol (2006) 17:846-53. doi:10.1681/ ASN.2005090986

23. O'Hare AM, Choi AI, Bertenthal D, Bacchetti P, Garg AX, Kaufman JS, et al. Age affects outcomes in chronic kidney disease. J Am Soc Nephrol (2007) 18:2758-65. doi:10.1681/ASN.2007040422

24. Coresh J, Astor BC, Greene T, Eknoyan G, Levey AS. Prevalence of chronic kidney disease and decreased kidney function in the adult US population: Third National Health and Nutrition Examination Survey. Am J Kidney Dis (2003) 41:1-12. doi:10.1053/ajkd.2003.50007

25. Hemmelgarn BR, Zhang J, Manns BJ, Tonelli M, Larsen E, Ghali WA, et al. Progression of kidney dysfunction in the community-dwelling elderly. Kidney Int (2006) 69:2155-61. doi:10.1038/sj.ki.5000270

26. Chronic Kidney Disease Prognosis Consortium, Matsushita K, van der Velde M, Astor BC, Woodward M, Levey AS, et al. Association of estimated glomerular filtration rate and albuminuria with all cause and cardiovascular mortality in general population cohorts: a collaborative meta-analysis. Lancet (2010) 375:2073-81. doi:10.1016/S0140-6736(10)60674-5

27. Muntner P, Bowling CB, Gao L, Rizk D, Judd S, Tanner RM, et al. Age-specific association of reduced estimated glomerular filtration rate and albuminuria with all-cause mortality. Clin J Am Soc Nephrol (2011) 6:2200-7. doi:10.2215/ CJN.02030311

28. John R, Webb M, Young A, Stevens PE. Unreferred chronic kidney disease: a longitudinal study. Am JKidney Dis (2004) 43:825-35. doi:10.1053/ j.ajkd.2003.12.046

29. Davies DF, Shock NW. Age changes in glomerular filtration rate, effective renal plasma flow, and tubular excretory capacity in adult males. J Clin Invest (1950) 29:496-507. doi:10.1172/JCI102286

30. Fliser D, Zeier M, Nowack R, Ritz E. Renal functional reserve in healthy elderly subjects. J Am Soc Nephrol (1993) 3:1371-7.

31. Fliser D, Ritz E, Franek E. Renal reserve in the elderly. Semin Nephrol (1995) 15:463-7.

32. Fuiano G, Sund S, Mazza G, Rosa M, Caglioti A, Gallo G, et al. Renal hemodynamic response to maximal vasodilating stimulus in healthy older subjects. Kidney Int (2001) 59:1052-8. doi:10.1046/j.1523-1755.2001.0590031052.x

33. Hollenberg NK, Adams DF, Solomon HS, Rashid A, Abrams HL, Merrill JP. Senescence and the renal vasculature in normal man. Circ Res (1974) 34:309-16. doi:10.1161/01.RES.34.3.309

34. Van der Velde M, Bakker SJL, de Jong PE, Gansevoort RT. Influence of age and measure of eGFR on the association between renal function and cardiovascular events. Clin J Am Soc Nephrol (2010) 5:2053-9. doi:10.2215/CJN. 08851209

35. National Clinical Guideline Centre (UK). Anaemia Management in Chronic Kidney Disease: Partial Update 2015. National Institute for Health and Care Excellence: Clinical Guidelines. London, UK: Royal College of Physicians (2015).

36. National Kidney Foundation. K/DOQI clinical practice guidelines for chronic kidney disease: evaluation, classification, and stratification. Am J Kidney Dis (2002) 39:S1-266.

37. Rule AD, Amer H, Cornell LD, Taler SJ, Cosio FG, Kremers WK, et al. The association between age and nephrosclerosis on renal biopsy among healthy adults. Ann Intern Med (2010) 152:561-7. doi:10.7326/0003-4819-152-9-201005040-00006

38. Coresh J, Astor BC, McQuillan G, Kusek J, Greene T, Van Lente F, et al. Calibration and random variation of the serum creatinine assay as critical elements of using equations to estimate glomerular filtration rate. Am J Kidney Dis (2002) 39:920-9. doi:10.1053/ajkd.2002.32765

39. James MT, Hemmelgarn BR, Tonelli M. Early recognition and prevention of chronic kidney disease. Lancet (2010) 375:1296-309. doi:10.1016/ S0140-6736(09)62004-3

40. Eriksen BO, Ingebretsen O. In chronic kidney disease staging the use of the chronicity criterion affects prognosis and the rate of progression. Kidney Int (2007) 72:1242-8. doi:10.1038/sj.ki.5002472

41. Bolignano D, Mattace-Raso F, Sijbrands EJ, Zoccali C. The aging kidney revisited: a systematic review. Ageing Res Rev (2014) 14:65-80. doi:10.1016/j. arr.2014.02.003

42. Mascia S, Minutolo R, Sasso FC, D’Angiò P, Pacilio M, Sperlongano R, et al. Chronic kidney dysfunction in the elderly patient: physiological process or disease? G Ital Nefrol (2013) 30.

43. Zhou XJ, Rakheja D, Yu X, Saxena R, Vaziri ND, Silva FG. The aging kidney. Kidney Int (2008) 74:710-20. doi:10.1038/ki.2008.319

44. Fraser SD, Roderick PJ, May CR, McIntyre N, McIntyre C, Fluck RJ, et al. The burden of comorbidity in people with chronic kidney disease stage 3: a cohort study. BMC Nephrol (2015) 16:193. doi:10.1186/s12882-015-0189-z

45. Stevens LA, Coresh J, Levey AS. CKD in the elderly-old questions and new challenges: World Kidney Day 2008. Am J Kidney Dis (2008) 51(3):353-7. doi:10.1053/j.ajkd.2008.01.009

46. Glassock RJ, Winearls C. An epidemic of chronic kidney disease: fact or fiction? Nephrol Dial Transplant (2008) 23(4):1117-21. doi:10.1093/ndt/gfn086

47. Muscaritoli M, Molfino A, Bollea MR, Rossi Fanelli F. Malnutrition and wasting in renal disease. Curr Opin Clin Nutr Metab Care (2009) 12(4):378-83. doi:10.1097/MCO.0b013e32832c7ae1

Disclaimer: The authors are responsible for the content and writing of the paper. The manuscript is not under consideration for publication elsewhere.

Conflict of Interest Statement: The authors declare that the research was conducted in the absence of any commercial or financial relationships that could be construed as a potential conflict of interest.

The reviewers $\mathrm{CO}$ and $\mathrm{AD}$ and handling Editor declared their shared affiliation and the handling Editor states that the process nevertheless met the standards of a fair and objective review.

Copyright ( 2017 Lai, Amabile, Altieri, Mastroluca, Lai, Aceto, Crudo, D’Angelo, Muscaritoli and Molfino. This is an open-access article distributed under the terms of the Creative Commons Attribution License (CC BY). The use, distribution or reproduction in other forums is permitted, provided the original author(s) or licensor are credited and that the original publication in this journal is cited, in accordance with accepted academic practice. No use, distribution or reproduction is permitted which does not comply with these terms. 